\title{
El nuevo movimiento mapuche: hacia la (re)construcción del mundo y país mapuche
}

Resumen: El principal objetivo del presente ensayo es analizar los conceptos y praxis del Mundo Mapuche y del País Mapuche las cuales, es posible argüir, constituyen la síntesis de la demanda y propuesta de parte significativa del movimiento mapuche autonomista. Síntesis que conlleva una modificación cualitativa en la estructuración de los marcos cognitivos del movimiento, lo que ha significado la articulación embrionaria de una visión mapuche de la realidad que trascendería la dimensión social y política del movimiento para instalarse como elemento de índole más estructural, que ya no sólo enfrenta crecientemente a dos identidades distintas, sino que, también, a dos proyectos de sociedad, a dos países, a dos pueblos encapsulados en un mismo territorio geográfico, pero culturalmente diferenciados.

La aproximación al sujeto de estudio se realizará a través de la aplicación de algunos elementos de las teorías de los movimientos sociales, específicamente los marcos cognitivos, y además, desde el concepto de memoria colectiva.

Palabras clave: movimiento mapuche, mundo mapuche, país mapuche; identidad, marcos cognitivos, memoria colectiva.

\section{The new mapuche movement: towards the (re)construction of the mapuche world and country}

\begin{abstract}
The main objective of the present essay is to analyse the concept and praxis of Mapuche World and Mapuche country which, one could argue, constitute a synthesis of both, the demand and set of proposals of a significant part of the autonomous Mapuche movement. This implies a qualitative modification of the structuring of the movement's analytical frames which has resulted in the incipient articulation of a Mapuche view of reality that transcends the social and political dimensions of the movement, to install itself as a more structural type of element. It is no longer the confrontation of two different identities, but also of two projects of society, two countries, two people encapsulated in the same geographical territory, but being culturally distinct.
\end{abstract}

Key words: mapuche movement, mapuche world, mapuche country; identity, cognitive frames, colective memory

\footnotetext{
* Universidad Alberto Hurtado, Santiago, Chile. E-mail: tricot@cealc.cl
} 


\section{O novo movimento mapuche: para a (re) construção do Mundo e País mapuche}

Resumo: O principal objetivo do presente ensaio é analisar os conceitos e praxis do Mundo Mapuche e do País Mapuche as quais, é possível argüir, constituem a síntese da demanda e proposta de parte significativa do movimento mapuche autonomista. Síntese que implica uma modificação cualitativa na estructuración de os marcos cognitivos do movimento, o que significou a articulación embrionaria de uma visão mapuche da realidade que trascendería a dimensão social e política do movimento para se instalar como elemento de índole mais estrutural, que já não só enfrenta crescentemente a duas identidades diferentes, senão que, também, a dois projetos de sociedade, a dois países, a dois povos encapsulados num mesmo território geográfico, mas culturalmente diferenciados. A aproximação ao tema de estudo efetuará-se pela aplicação de alguns elementos das teorias dos movimentos sociais, especificamente os marcos cognitivos, e ademais, desde o conceito de memória coletiva.

Palabra-chave: Movimento Mapuche, Mundo Mapuche, País Mapuche; identidade, marcos cognitivos, memória coletiva.

Recibido: 01.10.2009

Aceptado: 26.10.2009

$* * *$

\section{Introducción}

Dicen los que saben, que los más antiguos de los antiguos estaban hechos de lluvia azul. Y así caminaban por el mundo, pintando mariposas y océanos sin pausa, descansando sólo en las noches más oscuras alumbrándose de luciérnagas tiernas. Algunos dicen que, en realidad, eran dioses orlados de viento que buscaban la mejor tierra para sembrar sueños y, de pronto, sin previo aviso, en una tormenta imposible de relámpagos y volcanes fulgentes, se dibujó en toda su morena hermosura la primera lagmien mapuche. Toda esta tierra es tuya, le susurraron con fuego para que jamás nunca se le olvidara, ni a sus hijos, ni a los hijos de sus hijos. Y así a la gente de la tierra se les dio el Meli Witran Mapu -los cuatro puntos cardinales- para que allí hicieran el amor sin prisa y, también sin urgencia, compartieran los frutos de sus entrañas que eran, les dijeron, de todos y de nadie. Que aquí podrían construir su Mundo y su País, y les dieron choroyes y arrayanes, quilas y bandurrias, lagos y montañas, y en el centro de su corazón les dibujaron un río tan bello y tan azulado que daban ganas de llorar en las desconcertantes madrugadas de rocío virgen. Hilar su Mundo y su País, les dijeron, pero, con un dejo de tristeza y con descomunal pesadumbre, entornaron sus ojos de lluvia para advertirles que desde allende los mares vendrían de yelmo y alabardas para matarlos a todos en nombre de un dios ajeno. Que tuvieran cuidado, porque aquende la muerte se vestiría de uniforme chileno y argentino; y todo se lo dijeron en tiempos en que no existían ni Chile ni Argentina, sino tan sólo el Wallmapu, el País Mapuche, su país de tierra fértil y pródiga y, por lo mismo, apetecible por forasteros de distinto signo. 
Así, aún perplejos ante la posibilidad de que les arrebataran sus tierras y sus sueños que apenas comenzaban, los mapuche se abocaron a la tarea de irisar su Mundo sustentado en Itrofillmongen, la vida en su conjunto, la biodiversidad, el equilibrio, el respeto. Al bienestar en armonía le llamaron Küme Felen; Küme Mongen a la calidad de vida y Nor-Felen a la ley natural o autorregulación de la naturaleza de las distintas dimensiones del Mundo Mapuche donde habitan los hombres y las fuerzas de la vida desde tiempos inmemoriales. O desde todos los tiempos, que es el tiempo mapuche, el justo que necesitaron para construir el Wallmapu. El País mapuche, que oteaba dos océanos y dos cordilleras, se nutrió de la lluvia azul de los más antiguos de los antiguos y del Ad Mapu para iluminar a los nagche, wenteche, lafkenche, williche, pewenche o puelche, mapuche todos, gente de la tierra para que nunca se les olvide. Empero, una noche cualquiera lo persiguieron, lo acorralaron, lo redujeron, lo radicaron a la fuerza y lo asesinaron a la fuerza en nombre de la civilización. Le usurparon el País Mapuche y le pulverizaron el Mundo Mapuche en nombre de la razón, de la riqueza y de aquella propiedad de la cual hablaba un dios extraño que gritaba la barbarie de los indios. Y los indios se guarecieron en sus silencios de indio para enfrentarse al egoísmo wingka, mientras bajo las piedras, en los recodos de los ríos, en las copas de los árboles, en los contrafuertes cordilleranos y en el fondo del mar, guardaban sus palabras, sueños, memorias, anuncios y denuncias, virtudes y vilezas, victorias y derrotas, amores y desamores, cantos y bailes, los primeros y los últimos pasos. Con especial cuidado escondieron el mapudungun, su lengua, y el origen del mundo y las leyes de la naturaleza. Todo, según cuentan, en un volcán en llamas donde sólo los kimche conocieron del secreto para evitar que el kimun mapuche ardiera en brasas y ceniza. Fue tal su sapiencia que, en las noches más opacas, desde sus ruka, sus campos y sus montes, salían sigilosos hombres, mujeres, ancianos y niños para dirigirse al volcán de la memoria. Allí recuperaban palabras, ritos, nombres, historias y, por sobre todo, el sueño de libertad que les mantenía vivos mientras el wingka les horadaba el alma. Los mapuche se negaban a morir o desaparecer en la ira de los vientos despiadados que venían del norte a lomo de caballo, en cureñas, de quepís, de sable y bayoneta, de fusil y revólver. Venían de la guerra para hacer otra guerra: de la civilización contra la barbarie, de la chilenidad contra la mapuchidad, intentando obliterar el Mundo y País mapuche para siempre.

Sin embargo, en todos los tiempos y en todas las épocas, el pueblo mapuche ha bregado, ora en la resistencia ora en la articulación de una demanda y propuesta colectiva, por la preservación y proyección de su Mundo y su País y, por lo mismo, el movimiento mapuche es de antigua data, habiendo recorrido diversas etapas, momentos, repertorio de acciones, elaboración de demandas y formas organizativas en la búsqueda de la modificación de su relación con el Estado y sociedad chilenas. Relación históricamente conflictiva y políticamente tensional donde la chilenidad y la mapuchidad constituyen el anverso y reverso de una matriz de dominación, a veces patente, otras latente, que parece ser permanentemente fortalecida desde el poder chileno y, simultáneamente, constantemente interpe- 
lada desde el poder alternativo mapuche. Es dicha interpelación, transformada en movimiento social y político, la que ha adquirido una multiplicidad de expresiones a través del tiempo, entrelazándose diversas estrategias que configuran una arquitectura de continuidades y rupturas, avances y retrocesos en el desarrollo del accionar colectivo mapuche. No obstante, a pesar de que el movimiento puede ser depositario y reservorio de la memoria de su propia historia y, de alguna manera, un movimiento continuo, es posible identificar puntos de inflexión que constituyen un cambio cualitativo en el modo de articulación de la demanda indígena, la cristalización de una nueva calidad en el accionar colectivo y, además, un transformación importante en la relación con el Estado y con la sociedad chilenas. Este giro movimental, es posible argumentar, se verificó a fines de 1997 en la zona de Lumako ${ }^{1}$, en el sur del país, cuando las comunidades de Pichilonkoyan y Pililmapu llevaron a cabo la recuperación de territorios que consideran ancestrales. Asimismo, procedieron a la quema de camiones de la forestal Bosques Arauco. Lo anterior puede percibirse como el inicio de una nueva etapa en la acción colectiva mapuche que se configura a partir de la irresolución del conflicto entre el Estado chileno y el pueblo mapuche. En Lumako se plasma, simbólicamente y de hecho, el surgimiento de lo que puede genéricamente denominarse el nuevo movimiento mapuche, habiéndose verificado un proceso de tránsito desde las reivindicaciones de índole más culturalistas y economicistas a aquellas de tipo autonomistas. Si bien es cierto que la demanda autonomista no en nueva ni ajena al movimiento mapuche (Ruiz 2007), lo que parece caracterizar al movimiento actual es la centralidad y transversalidad de dicha demanda, así como la visibilización y posicionamiento societal de la misma. Constituye el vórtice de todo su repertorio de demandas y acciones y el componente articulador de los elementos de cultura, territorio, identidad y movimiento socio-político.

Es en el marco de lo anteriormente descrito donde se inscribe el principal objetivo del presente ensayo: analizar los conceptos y praxis del Mundo Mapuche y del País Mapuche las cuales, es posible argüir, constituyen la síntesis de la demanda y propuesta de parte significativa del movimiento mapuche autonomista. Síntesis que conlleva una modificación cualitativa en la estructuración de los marcos cognitivos del movimiento, lo que ha devenido en la articulación embrionaria de una visión mapuche de la realidad que trascendería la dimensión social y política del movimiento para instalarse como elemento de índole más estructural que ya no sólo enfrenta crecientemente a dos identidades distintas, sino que, también, a dos proyectos de sociedad, a dos países, a dos pueblos encapsulados en un mismo territorio geográfico, pero culturalmente diferenciados, donde la otredad de uno es la mismidad del otro, que se afirma identitaria y culturalmente para, a su vez, resistir esa otredad. A pesar de lo señalado, somos concientes que no necesariamente todo el movimiento mapuche posee, postula o refleja la confrontación de dos proyectos estructurales y, por

\footnotetext{
${ }^{1}$ Para un completo análisis de la importancia de Lumako en el desarrollo del nuevo movimiento mapuche, ver: (Tricot T, 2009).
} 
lo tanto, nuestra aproximación se refiere, más precisamente, al movimiento autonomista. Además, es necesario puntualizar que, producto de su heterogeneidad, el movimiento mapuche autonomista se mueve entre la reconstrucción y la construcción del Mundo y País mapuche. Dicho proceso (re)constructor, por lo tanto, posee dos dimensiones: una más culturalista y otra más política, aunque ambas llevan implícita la necesidad de la autodeterminación para viabilizar el mencionado proceso de (re)construcción. Y, además que, en el contexto de la realidad del Estado-nación chileno, la libre-determinación adopta la forma concreta de autonomía, es decir, de una soberanía negociada.

\section{Marcos de análisis del movimiento mapuche: desde la memoria a la acción colectiva}

El movimiento mapuche autonomista actual constituye un actor y sujeto definido por su heterogeneidad y diversidad, su referencia a un pasado común, a una matriz cultural, a una identidad colectiva histórica y a una aspiración de unidad política en un territorio: el Wallmapu. Movimiento donde pareciera existir un proceso de construcción conciente y de carácter colectivo en torno a las ideas de cultura, identidad, territorio y política, todo lo cual constituiría al movimiento y, simultáneamente, el movimiento los constituiría a éstos. La construcción de la identidad colectiva del movimiento es de carácter biforme: de afirmación identitaria propia y de cuestionamiento a la otredad, de afirmación simultánea de la igualdad y la diferencia. Afirmación de la mapuchidad e interpelación a la chilenidad lo cual, por cierto, explicaría la imbricación entre identidad colectiva y movimiento social como expresión o consecuencia de un conflicto pre-existente y, además, contribuye a entender la relación entre identidad y acción colectiva, toda vez que la identidad da sentido a la acción y la acción colectiva fortalece esa misma identidad. En suma, la identidad como un constructo y el movimiento social como un constructor de dicho constructo, pero, además, arquitecto pro-activo de entramados analíticos que conforman procesos de enmarcamiento cruciales para el desarrollo del movimiento. La elaboración de marcos de análisis busca definir, interpretar y expresar la realidad. En este contexto, el concepto de marco parece ser más adecuado que el de ideología ${ }^{2}$ para intentar explicar los procesos internos que se verifican en el movimiento en cuanto a diagnóstico, pronóstico y motivación, las tres direcciones en las cuales operarían los marcos. Estos últimos entendidos como especies de lentes a través de los cuales el movimiento tamiza la realidad, un prisma que descompone la realidad en distintos elementos que buscan ordenarla, articulando elementos existentes y, simultáneamente, orientando la acción colectiva. Los marcos son como plantillas interpretativas que buscar determinar la esencia del conflicto, sus causas, los

\footnotetext{
${ }^{2}$ Es menester señalar, sin embargo, que hay algunas organizaciones mapuche, como la Coordinadora Arauko-Malleko-CAM, cuyos planteamientos deben analizarse también desde parámetros ideológicos para su cabal comprensión.
} 
principales actores, el posible derrotero del conflicto, entre otros. Sirven también para construir o reconstruir identidad, para -de algún modo-naturalizar su demanda y su propuesta. Pero, además, el focalizarse en el estudio de la identidad como constructo y de la elaboración y operación de marcos cognitivos, permite circunvalar y superar la tendencia implícita en otras teorías, que se centran en lo que denominan ciclos de protesta social al analizar lo visible y patente, excluyendo los períodos de latencia de los movimientos sociales los cuales, es posible sostener, son tal vez los más extensos. Y en ambos periodos se van gestando elementos que no sólo remiten a la contingencia política o al accionar colectivo, sino que también a un pasado común como pueblo y como nación. Es decir, los marcos cognitivos se nutren del Mundo Mapuche y del País Mapuche y se sustentan y entrelazan mediante la memoria colectiva. Aseverar que existe o subsiste una relación con el pasado no equivale a plantear que el movimiento mapuche en su conjunto haya estructurado procesos de enmarcamiento cuyo referente central y único sea el pasado. Por el contrario, la heterogeneidad del movimiento -una característica histórica por lo demás- implica diferencias y matices, desacuerdos y contradicciones en la lectura de la realidad y, también, en el accionar y formas organizacionales. En este sentido, se evidencian posiciones y propuestas culturalistas, vinculadas más bien a cierto grado de fundamentalismo étnico; por otro lado, proyectos asociados a una identidad y territorio particulares y, finalmente, existen propuestas relacionadas con demandas y aspiraciones de naturaleza nacionalitaria que reivindican la condición de los mapuche como un pueblo nación y cuyo referente no es sólo un pasado inerte, sino que un proyecto de "país como construcción política por hacer” (Painemal, 2009). En todos los casos, se puede declarar, la memoria mapuche parece estar presente como vehículo imbricador de pasado, presente y futuro, aunque, claro está, con gradaciones políticas importantes. Asimismo, tampoco se puede sostener que la mayoría de los mapuche, sea en las comunidades o en las zonas urbanas, sean participantes o integrantes activos del movimiento ni que el movimiento represente a todo el pueblo mapuche. El movimiento mapuche es una expresión concreta de acción colectiva de un segmento del pueblo mapuche que, en su diversidad, posee un discurso autonómico que es, a su vez, reflejo de procesos de enmarcamiento que contemplan conceptos seminales como identidad, territorio y autonomía, porque el movimiento "ha incorporado elementos de nuestra cultura como práctica política" (Millalen, 2009) y, porque, "la idea de territorio no se puede concebir sin la idea de pueblo" (Ibidem). El movimiento mapuche, entonces, se expresa en una serie de movimientos, a veces contradictorios, otras complementarios, que circulan entre tierra y territorio, lo cultural y lo nacionalitario, de marcos a ideología, de una autonomía relativa a la liberación nacional, de formas convencionales a no convencionales de accionar y de organizarse. Sin embargo, dicha heterogeneidad no constituye una particularidad del movimiento mapuche, sino que es propia de los movimientos sociales. Y, en el caso especifico de los movimientos indígenas, es permeada por la memoria histórica, no exclusivamente la memoria antigua, sino que también la más reciente, y ello se refleja, por ejemplo, en su repertorio de acciones, pues si bien es cierto "la acción de tipo colectivo responde a la historia, a la memo- 
ria con la que cuenta cada grupo” (Tricot Tokichen, 2007), éstas son susceptibles de modificación y, además, de préstamos culturales, especialmente en un mundo globalizado. Por lo tanto, co-existen la antigua memoria y la memoria reciente que se relacionan con el Mundo y País mapuche culturalmente construido e internalizado donde "lo histórico forma parte de un bagaje ahí presente, personal y colectivo, pero donde se incluyen elementos de presente y se planean y visualizan elementos del futuro" (Painemal, 2009).

En cualquier caso, conceptualizamos a la memoria colectiva como un proceso de reconstrucción del pasado por parte de un conglomerado humano particular que apunta a la preservación del mismo; no es una mera evocación de recuerdos y momentos específicos, sino que una actualización articulada de lo pretérito, una organización del pasado en el presente. Dicha memoria colectiva define al grupo, lo constituye y, además, no sólo sintetiza huellas del pasado, sino que, por sobre todo, constituye condición de posibilidad del futuro en tanto reproducción cultural e identitaria. Es posible argumentar que los conceptos de memoria, historia y olvido, coparticipan de un horizonte común, toda vez que configuran un andamiaje teórico donde se inserta la interrogante por la representación del pasado en el presente. Mas la propincuidad de dichos términos no se circunscribe a lo exclusivamente epistemológico, sino que se manifiesta en la práctica social y en directa vinculación con el poder político, puesto que la historia -sustentada en la memoria- constituye una narración de acontecimientos pretéritos donde, en dependencia de la forma concreta de resolución de conflictos societales, puede ser más o menos parcial, más o menos objetiva, más o menos verdadera. Por su parte, la memoria pareciera ser falible, maleable y vulnerable. Sin embargo, no puede haber historia sin memoria, aunque sí puede haber memoria sin historia, puesto que para hacer historia se debe, necesariamente acorde a Ricceur, realizar una operación historiográfica, la cual consiste en trascender las limitaciones de la memoria por intermedio de la escritura de la historia. Es decir, la historia se construye a partir de la memoria, no obstante, dicha acción no está exenta de riesgos, porque si bien es cierto existe confianza en "la capacidad de la historiografía para ensanchar, corregir y criticar la memoria, y así compensar sus debilidades tanto en el plano cognitivo como pragmático” (Ricceur 2000:190), no es menos cierto que en el proceso se puede perder la mera esencia de la memoria como fuente primaria y veraz de información, fundamentalmente mediante el testimonio oral. Y la memoria mapuche es fundamentalmente oral, una narración colectiva transmitida de generación en generación en la forma de una conjunción de elementos cosmovisionales, históricos y culturales que reproducen un pasado, valores, simbología, normas, tierras, territorio y prácticas sociales compartidas. La memoria mapuche constituye, en rigor, un colosal memorial al Mundo y País Mapuche. Toledo sostiene que "la memoria para los pueblos indígenas no es sólo mera resistencia, y su ejercicio no es sólo un derecho cultural, como puede ser el derecho a hablar la propia lengua y creer en los propios dioses. El derecho a la memoria está íntimamente vinculado al principio de libre determinación” (Toledo 2007:13) y éste se ejerce en un territorio, entendido como un 
constructo social que sólo adquiere sentido a través del significado que le otorga el ser humano. Es mucho más que su dimensión física: es un espacio de dominación caracterizado por relaciones de poder. Espacio concreto donde se verifican relaciones sociales, interacción entre personas y colectividades y con la naturaleza. Es un espacio habitado por la memoria y la experiencia de los pueblos; un espacio construido por el ser humano a través del tiempo y apropiado por este.

En el marco de lo anteriormente señalado, conceptualizamos al Mundo Mapuche como la conjugación e interrelación de elementos tangibles e intangibles que estructuraron el mundo antiguo y que producen sentido: el sentido mapuche y que se busca (re) construir en las nuevas condiciones de un Estado-nación negador de la otredad. Por su parte, el País Mapuche, el Wallmapu, constituye la expresión territorial del Mundo Mapuche, espacio de anclaje de su memoria, fundamentado en la cosmovisión mapuche y, además, en el Ad Mapu, sistema de regulación del comportamiento individuad y colectivo dentro de los diversos espacios que componen el territorio y que se dividen en las cuatro partes de la tierra o Meli Witran Mapu donde se han constituido desde siempre diferentes identidades territoriales.

\section{(Re) construyendo el futuro entre la cultura y la política}

La memoria histórica, su recuperación, preservación y reproducción, constituyen un elemento central en el surgimiento y desarrollo del nuevo movimiento mapuche, toda vez que articula el puente entre un antes y un después y, además, agencia la resistencia identitaria y la demanda autonómica. Asimismo, posiciona una memoria alternativa a la memoria dominante, una memoria ancestral a una memoria reciente, como lo es la chilena. De esta manera, el movimiento mapuche pareciera no solamente erigir, de manera sistemática, una narrativa distinta a la oficial, sino que también intentar minimizar las posibilidad del Olvido. Este último es de carácter dual, puesto que se manifiesta como pérdida de memoria y, también, como omisión de información por cualesquiera razones. Es decir, en todo proceso de reconstrucción del pasado, ya sea a través de la memoria o de la escritura de la historia, existe un extravío, acaso irreparable, en los laberintos de la memoria humana. Se verifica, entonces, una tensión permanente entre memoria y olvido y, por extensión, entre memoria, olvido e historia. En todo caso, "casi nunca se olvidan del todo los acontecimientos emblemáticos ocurridos en momentos de conflicto, violencia y sufrimiento” (Loveman y Lira 2001: 106), y es indudable que el pueblo mapuche ha pervivido en conflicto, violencia y sufrimiento permanentes desde el surgimiento del Estado-chileno. El problema, es posible argumentar, radica en el hecho de que ni la memoria, ni el olvido ni la historia son simples narrativas, sino que prácticas sociales concretas que se materializan en contextos socioculturales también concretos. Benjamin sostenía que "la verdadera imagen del pasado transcurre rápidamente. Al pasado sólo puede retenérsele en cuanto imagen que relampaguea, para nunca más ser vista, 
en el instante de su cognoscibilidad” (Benjamin, 1955: 3), pero ello no impide la búsqueda de la verdad, sino que más bien advierte acerca de la necesidad de que el proceso cognoscente se realice adecuadamente a objeto de atravesar esa imagen del pasado y capturar ese momento o ese conjunto de momentos como una forma concreta de representar el pasado en el presente. En este contexto, la negación de la memoria y de la representación histórica al pueblo mapuche, responden a un contexto específico de resolución de un conflicto societal donde el poder político chileno ha intentado desde siempre subsumir la memoria y la historia mapuche, su Mundo y su País, en la memoria e historia chilenas que se instituyen como las únicas válidas. Considerando lo anterior, se puede argüir que el movimiento mapuche ha comprendido bien que en este país se han configurado espacios de poder donde el olvido es más importante que la memoria, pues la memoria cuestiona a ese propio poder. Lo cuestiona desde el pasado, desde el territorio, desde la cosmovisión y cosmogonía mapuche. Lo cuestiona desde el presente, desde el derecho al reconocimiento, la auto-representación y la autonomía como pueblo-nación, y la (re)construcción del Mundo y País mapuche forma parte integral de dicho esfuerzo colectivo.

El movimiento mapuche actual, aquel que remite a Lumako, pero que, sin duda, es depositario de otros tiempos, ha elaborado marcos cognitivos que, en lo fundamental, dan cuenta de la relación asimétrica entre el Estado y la sociedad chilenas y el pueblo mapuche, toda vez que se ha materializado una díada que ha devenido en un claro continuum histórico. Son dos términos de una misma ecuación: dominación-dominado, donde lo primero es agenciado por el Estado-nación y, lo segundo, por el pueblo mapuche. Si bien es cierto que es posible constatar modificaciones en la forma específica de dominación, ello no altera la esencia de la relación, puesto que siempre ésta se ha determinado desde el poder. Salvo al comienzo de la república, cuando se evidenció una cierta tendencia, acaso nostálgica, al reconocimiento del indígena abstracto y fosilizado en el tiempo, el Estado-nación -que se constituye como uninacional y unicultural, además de políticamente unitario-procedió a la negación de la otredad y a la invisibilización coercitiva de la diferencia. La imposición de la identidad y cultura chilenas conllevó, simultáneamente a la negación del otro, la incrustación en el imaginario colectivo de una falsa dicotomía entre civilización y barbarie como un conflicto aparentemente inherente a la modernidad latinoamericana. Después de todo, como sostuviera Vicuña Mackenna, el indígena no era “...sino un bruto indomable, enemigo de la civilización porque sólo adora todos los vicios en que vive sumergido, la ociosidad, la embriaguez, la mentira, la traición y todo ese conjunto de abominaciones que constituye la vida del salvaje. Se invoca la civilización a favor del indio i ¿qué le debe nuestro progreso, la civilización misma? Nada, a no ser el contajio (sic) de barbarie con el que ha inficionado nuestras poblaciones, por lo que la conquista del indio es, esencialmente, como lo ha sido en Estados Unidos, la conquista de la civilización” (Vicuña Mackenna, 1868: 7).

Pero el movimiento mapuche no se circunscribe a invocar el pasado para desobstruir el tráfago de la memoria histórica impuesto por la auto- 
denominada sociedad mayor, o reivindicar el legítimo derecho a una narrativa alternativa, sino que -por sobre todo- para, en lo medular, proponer la (re) construcción del Mundo y País mapuche como una necesidad en tanto pueblo distinto en condiciones históricas cualitativamente diferentes. Además, se trata de desplazar las fronteras de la memoria para fortalecer las fronteras identitarias, culturales y territoriales ante la usurpación de la cual han sido objeto. Porque, es desde el poder donde no sólo se han trazado las demarcaciones identitarias, sino que también las políticas económicas e ideológicas que conforman una arquitectura matricial de dominación y negación del Mundo Mapuche y del País Mapuche. Fue así ayer y continúa siendo así hoy, porque la reducción y asimilación culturales constituyen parte integral de las estructuras de dominación chilenas que han fluido -con mayor o menor intensidad- a través de diversos hitos históricos: desde la ocupación militar del territorio indígena, la colonización, la reducción, la radicación, la dictadura militar, la división de las comunidades, la penetración forestal y los gobiernos civiles actuales. Estos dos últimos componentes imbricados por la imposición y consolidación del modelo económico neoliberal que ha significado la sistemática pauperización y marginalización de los mapuche en el marco de un sistema capitalista dependiente.

Si bien es cierto que uno podría concordar con Mouffe que “aceptar la naturaleza del poder como algo inherente a las relaciones sociales implica renunciar al ideal de una sociedad democrática como realización de una perfecta armonía” (Mouffe, 2003), no podemos menos que argumentar que, en el caso específico de la relación Estado chileno-pueblo mapuche, no existe siquiera una imperfecta armonía. Por lo tanto, no puede sorprender que un segmento de los mapuche se haya refugiado en la etnicidad como estrategia de lucha y forma primordial de supervivencia. Se han refugiado en su Mundo y en su País que remiten a un relato y mito fundante y que han sido recogidos por el movimiento en el proceso de enmarcamiento que interpreta la realidad y orienta la acción del mismo. El Mundo Mapuche no es sólo argamaza de polvo de estrellas y llanto de mujer primigenia, sino que una totalidad percibida como real y naturalizada por la memoria histórica. Ello pareciera refrendar el aserto de "que la cultura conserva una alta utilidad como instrumento para la afirmación de una diferencia local e histórica que viene asociada a posicionamientos instrumentales u objetivos políticos. Es decir, en términos sociológicos, cultura para poco; en términos políticos, cultura para mucho (para demasiado quizás) (Mascareño, 2007:62). No obstante, a pesar de que el movimiento mapuche -y el movimiento indígena a nivel continental- han politizado la cultura o culturizado la política, ello no significa que la identidad y la cultura puedan ser reducidas a una mera narración sin sustento objetual. En otras palabras, no es adecuado plantear que "la narrativización del sí mismo es un proceso necesariamente ficcional, si es que por eso se entiende la ausencia de una base real de la narrativa. Hay una diferencia entre literatura y relato identitario, así como la hay entre literatura y teoría” (Larraín, 2007: 117), y bajo estos parámetros, parece claro que el discurso identitario del movimiento mapuche articula un conjunto de elementos culturales considerados y percibidos como 
reales y que, por lo demás, remiten a una totalidad denominada Mundo Mapuche, es decir, una conjunción de elementos materiales e inmateriales que producen el sentido mapuche. Y fueron sus antepasados, acorde a Armando Marileo, gempin lafkenche, quienes "llegaron a determinar y explicarse la estructuración de su propio mundo, es decir, lograron comprender, articular e interrelacionar todos y cada uno de los elementos que constituyen el mundo mapuche” (Marileo, 1998: 3). Estos elementos son, entre otros, y de acuerdo al mismo autor, religión, familia, tierra, identidad, autopertenencia, origen, memoria cultural. Un mundo de equilibrio y armonía. Empero, a pesar de existir ciertos rasgos esencializantes en la construcción identitaria del discurso de una parte del movimiento mapuche, y acaso también en su referente cultural, ello no significa que a la cultura se la entienda y viva como una singularidad estática, suspendida en el tiempo e irrepetible. Aunque, claramente, poseería un alto grado de integración y persistencia desde cuya fuente se alimenta el discurso de la identidad. Asimismo, tanto el territorio social como el simbólico constituyen espacios de anclaje de la memoria ancestral y referentes objetivos de la historia colectiva mapuche, aunque sectores del movimiento mapuche señalan que "se rompió aquello de la identidad asociada a un lugar, sino que se diversificó la identidad; hay un hilo conductor, una historia familiar, una historia comunitaria, una historia política, una historia económica también, de carencias, de situaciones complejas en el ámbito comunitario, de aniquilación, y eso ya nos hace ser parte de un conglomerado particular” (Painemal, 2009).

En cualquier caso, hablar de un proceso (re) constructor implica la restauración parcial de un Mundo y País previamente existentes o, al menos, de algunos de sus elementos componentes y, por ende, el conocimiento de los mismos. Y, en este sentido, parece importante establecer que en la cultura mapuche, la concepción de pasado se entiende como un concepto genérico y abstracto sin referentes empíricos precisos susceptibles de ser situados en un principio o en fin de algún fenómeno o evento. Sin embargo, ello no obsta para que los mapuche posean una idea concreta acerca de su origen como pueblo y cultura. Además de la génesis del Mundo Mapuche, simbolizada en aquella hermosa estrella que desciende y explosa flores tras la furia de Fütran Newen, existen otros eventos que perviven en la memoria colectiva y que se expresan fundamentalmente mediante la oralidad y en las formas de diálogos solemnes: Pentukum, y diálogos de índole más cotidiano y de referencia personal directa: Y, más específicamente, en la forma de Epew, que son relatos vinculados a la ficción, y Piam que, a su vez, son narraciones de alto nivel de abstracción que remiten a los orígenes, evocando y transmitiendo conocimientos cosmovisionales y cosmogónicos del pueblo mapuche. Todo ello, además, complementado mediante los consejos de los ancianos y el sistema valórico que informaba y determinaba la relación entre los mapuche y de éstos con la naturaleza donde la Ñuke Mapu, la madre tierra, poseía una centralidad cardinal. Porque en aquel mundo, la tierra no tiene un sentido utilitario, en consecuencia, se toma de ella, como indica Chihuailaf, solamente "lo que nos sirve en el breve paso por este mundo, sin esquilmarla, así como ella nos toma -poco a poco- para transformarnos en agua, aire, fuego, verdor” (Chihuailaf 2008:11). Y se puede 
advertir que, gradualmente, el movimiento mapuche ha ido incorporando los elementos constitutivos del Mundo Mapuche en su discurso y praxis; es, de alguna manera, la memoria en movimiento y la identidad en movimiento, todo lo cual cumple un rol doble: de cohesión y movilización interna y, simultáneamente, de diferenciación externa. En ambos planos se trata de afirmación de la identidad étnica, y en algunos casos nacional, mediante la afirmación de la mismidad y demarcación clara de la otredad en la perspectiva de la (re)construcción de aquella comunidad imaginada que es la nación. Y esta comunidad se ha desarrollado y se continúa articulando en un espacio concreto como lo es el territorio, espacio constitutivo de la cultura e identidad mapuche, donde co-existen la cosmovisión, la comunidad de la sangre o Küpan, la identidad territorial o Tüwun; las tradiciones ancestrales, la memoria cultural, el andamiaje social, el idioma. El Mundo y País mapuche se (re) construyen en dicho espacio, del mismo modo que el nuevo sujeto social y político dimana de estos y del territorio, pues el territorio no sólo constituye un mero paisaje ideológico o demanda fundamental del movimiento mapuche, sino que, por sobre todo, se asume que es en este territorio mapuche donde se ha vivido desde siempre, y ese espacio vital es, por lo tanto, un universo de significados culturalmente adscritos. En otras palabras, es un constructo mapuche que articula su Mundo y su País integrando objetividad y subjetividades, apropiándose simbólicamente del territorio, aunque la representación de este último es ya de suyo una forma particular de territorialidad y, en cierto sentido, una expresión de poder. El Wallmapu es el correlato territorial del Mundo Mapuche y ha existido desde tiempos inmemoriales a ambos lados de la cordillera, es decir, tanto en el Gulumapu como en el Puelmapu. En carta dirigida al Ministro de la Guerra y Marina de la Republica Argentina, Julio Argentino Roca, y al coronel Conrado Villegas, en 1879, el lonko Valentín Sayweke, señalaba que su padre le había dado a conocer que "santiago (sic) de Chile, y otras varias Repúblicas, Provincias, departamentos, y billas (sic), habían sido todos poblados de razas Indígenas; hocupando (sic) hoy los cristianos y recibiendo números perjuicios los pobres indios criollos de aquella américa (sic) ...” (Pavez 2008:721). Y, actualmente, continúan los mismos perjuicios a los descendientes de aquellos indios criollos; de hecho, concomitantemente con la usurpación identitaria, la usurpación de la memoria y de la historia, se ha materializado la usurpación territorial. Por lo mismo, ya a fines del siglo antepasado, una misiva al presidente de la república de Chile, señalaba que “...ya no nos es posible soportar por más tiempo la cruel tiranía que sobre nosotros pesa. Las autoridades en representación del Estado i a nombre de la Ley, cooperan al despojo que nos hacen los especuladores de tierra y animales en la frontera, obligándonos a abandonar la que tanto amamos i en que hemos vivido con nuestros padres, en la que sus restos descansan, con la que hemos alimentados a nuestros hijos i regado con nuestra sangre” (Ibidem: 805). Es la memoria angustiada, el mapuche que experimenta la reducción de su País y la desintegración de su Mundo; ya no es sólo la pérdida de tierras antiguas, sino que de su propia existencia. Y así lo ha entendido el nuevo movimiento mapuche que, al igual que su ancestro, comprende que una cultura de resistencia es limitada $\mathrm{y}$, necesariamente, debe transformarse en propuesta política y autonómica 
para generar las condiciones que permitan, no sólo la subsistencia, sino que su proyección como pueblo y nación, como "comunidad de destino”. 3

Y para construir aquella comunidad de destino el mapuche preservó elementos de su Mundo y su País, aunque -obviamente- no de manera inalterable. Para Mariman, "esa institucionalidad forjada milenariamente cuenta con un conocimiento sistematizado, con agentes reconocidos, con espacios de socialización y procedimientos para la proyección singular e independiente a los impuestos por el estado-nación. Sobre esos soportes se logró entender lo humano, lo natural, lo espiritual, lo medicinal, las normas sociales, la regulación de los conflictos, la organización y obviamente sirvieron para captar el fenómeno de la alteridad. Todo lo mencionado crea un sistema real y legítimo, el que ayudó a controlar las inmensas extensiones territoriales del Wallontu Mapu y a dar gobernabilidad a una nación” (Mariman 2003: Prólogo). De este modo, se sintetiza la ilación entre Mundo y País mapuche, entre memoria, presente y futuro. Además, se grafica la interrelación entre territorio, cultura, identidad. Y pueblo mapuche, aquella entidad colectiva compartiendo un origen común y rasgos similares en su heterogeneidad. Y nación mapuche, aquel conglomerado humano donde se entremezclan la pertenencia cultural y la pertenencia política. De hecho, un segmento importante del nuevo movimiento mapuche postula la noción de pueblo-nación como el sujeto colectivo que agenciará su historia en la forma concreta de (re) construcción del Mundo y País mapuche. Es en este contexto que se rescatan y reproducen elementos componentes del Mundo Mapuche para rearticular "un modelo de sociedad donde Itrofillmongen es todo el sistema de vida en equilibrio. Donde Küme Fellen es el bienestar en armonía y Küme Mongen la calidad de vida. Y Nor-Felen es la ley natural o la autorregulación de la naturaleza” (Reiman, 2007). En otras palabras, ya sea en sus expresiones más etnicistas o en aquellas de intencionalidad nacionalitaria, para el nuevo movimiento mapuche, la cultura continúa siendo un referente fundamental. Además, parece claro que "sin el territorio no hay cosmovisión y, tampoco, sin la lengua, para que se pueda entender y luego practicar estos elementos explicativos, microcósmicos, filosóficos. En la cosmovisión mapuche están incorporados elementos de fondo que han estado durante 14 mil años; ahí esta el concepto del mundo y del territorio mapuche, ahí están los conceptos y los elementos constitutivos desde el punto de vista político, ahí están los elementos trascendentes que permiten la proyección de un pueblo” (Quilaqueo 2009). Entonces, la lucha no puede diferenciarse entre cultural y política, entre étnica o nacionalitaria, pues "lo mapuche es una cosa integral, holística, no podemos separar las cosas, no puede ser político por un lado, ni territorial, ni cultural, ni identitario, tiene que ser todo" (Ibidem). Sin embargo, y a pesar de esta línea argumental, para los sectores nacionalistas mapuche, se trataría de un proceso de construcción más que de reconstrucción de lo mapuche, y dicho proceso posee un carácter claramente político que requiere de espacios e instrumentos de interlocución con el Estado chileno, porque la autodeter-

${ }^{3}$ Concepto utilizado por Wallmapuwen, partido nacionalista mapuche. 
minación se conquista Es decir, dado el contexto de los estados nacionales, lo que se reivindica -más que un Mundo o País pasado y estático- son ciertos principios y valores mapuche que se pudiera incorporar dentro del accionar político. En este contexto es factible "retomar ciertos elementos culturales o del Ser mapuche, más específicamente, cuatro principios: la persona, el che, se basa en el kimun, en el saber mapuche; en la fuerza, la energía o newen; en el kume, el estar bien, es decir, estar bien de espíritu, pero también materialmente. Y, en la rectitud, la honorabilidad. Son principios transversales del Ser mapuche que necesariamente deben cruzar el accionar político. Podemos recuperar estos elementos y convertirlos en elementos orientadores de nuestras acciones políticas como personas, pero también como sociedad" (Quilaqueo 2009). En otras palabras, más que reconstruir la totalidad de un Mundo y un País fosilisados en el tiempo y en el espacio, se trata de recuperar ciertos valores y principios nucleares, además, por cierto, del idioma, tradiciones y prácticas sociales que han pervivido. Y en este sentido, para otros sectores del movimiento mapuche, la lucha también posee una dimensión cultural y espiritual fundamental, toda vez que se vincula a un mandato empíreo. A los pueblos, se señala, se les dejó en un lugar determinado "y en ese lugar determinado tienen un rol que cumplir en esta tierra. Y al entender este rol, eso hace que la lucha no sea solamente economicista, sino que espiritual. Yo tengo que defender el mandato que me dieron y ese mandato es conservar la naturaleza; luchar porque se mantengan nuestros recursos naturales, producir el equilibrio del Nag Mapu, de la tierra en sí, que es algo integral” (Reiman 2009).

En todo caso, ningún proceso (re)constructor, en cualesquiera de sus dos dimensiones, puede fructificar si no se resuelve el problema de la autodeterminación y eso es un problema político, puesto que se relaciona con el poder y no se reduce sólo a lo cultural o a lo étnico. Lo mapuche, la mapuchidad y el Ser mapuche constituyen, de alguna manera, un poder alternativo, la otredad negada por el Estado-nación. El otro que, desde la perspectiva mapuche, no es tal, sino que es simplemente el Ser mapuche que siempre ha existido y que, para una machi, es "una flor que florece constantemente, y que constantemente está pidiendo agua y ahí está: un gran copihue rojo que no se destiñe jamás y al que siempre le han dado agüita y de la lluvia que caiga del cielo, entonces para mi es vida, es luz, es lucha (Ñanko 2009). Aún así surge la interrogante: ¿ Se puede hablar aún de cultura mapuche, considerando los profundos movimientos telúricos a los cuales ha sido sometida? ¿Es posible continuar hablando de cultura sin reducirla sólo a su carácter instrumental y a su utilización por parte de las organizaciones mapuche? Para Saavedra, la cultura mapuche está plenamente articulada a una historia mayor, la chilena, que la sobredetermina y la transforma objetivamente. "No existen sociedades ni grupos étnicos mapuche que ejerzan control cultural sobre los elementos culturales propios de una cultura mapuche "(Saavedra, 2002:208). "La población mapuche actual forma parte de la cultura y la sociedad chilena y de los círculos y áreas culturales a los que esta pertenece...” (Ibidem: 2009). De aquí el autor colige que la mapuche es tan sólo una cultura de resistencia, es decir, las prácticas culturales remanentes serían residuales y se manifestarían po- 
líticamente, especialmente en las comunidades rurales. No es distinto, a pesar de provenir de acervos intelectuales muy diferentes, a lo señalado por Clifford, para quien las tradiciones se desvanecen, lo que dificultaría el conceptualizar la diversidad humana como algo inscrito en culturas cerradas, por lo tanto propone entenderlas como un orden emergente de culturas hibridas producto de la multiplicidad de intercambios que se dan a todo nivel. Desde esta perspectiva la cultura mapuche, entendida como un todo integrado, no existiría, lo cual es congruente con la idea de que el concepto original de cultura es inadecuado para entender "sociedades funcionalmente diferenciadas modernas, precisamente porque ellas licuan los contenidos tradicionales y deconstruyen las estructuras normativas” (Mascareño, Ibid: 69). Sin embargo, el movimiento mapuche se ha abocado a un luengo proceso de rescate y (re) construcción cultural y política, en la configuración concreta del Mundo y País mapuche, y ello ha sido posible sólo porque dichos contenidos tradicionales y estructuras normativas se han mantenido en el tiempo con una persistencia y consistencia que sirven de base y viabilizan el proceso (re) constructor. Ello no significa, y los propios mapuche lo destacan y critican, un esencialismo a ultranza que enfatizaría la diferencia por sobre la convivencia, la mapuchidad por sobre la chilenidad, pues la cultura, en este contexto, se utiliza como mecanismo diferenciador absoluto que puede devenir en una especie de dictadura étnica ((Mariman 2006), pero sí significa que existe una referencia cultural original a la cual se alude y a la cual se le intenta (re) construir en condiciones históricas distintas.

En este marco, la cultura mapuche -para los propios mapuche- no es un alma perdida y desarraigada, ni tampoco una entidad híbrida, como sostendría Clifford (Clifford 1995), sino que una totalidad referencial, un Mundo y un País que remiten a un relato fundador común. Es la historia del pueblo-nación mapuche que alude a un origen singular de lágrimas de ira, volcanes fulgentes, ríos añil y, además, al telúrico orgasmo cósmico entre la luna y el sol que preñó de ternura a la estrella mujer, útero primario de los mapuche. Entonces, la identidad es ancestral y no coyuntural, pero es cambiante, permeable y con capacidad de asombro. Es una referencia nuclear, más que una esencia inmutable, el epicentro de una cultura que se resiste a morir y la cual, en el proceso, se adapta a entornos cambiantes. Para algunos esto quiere decir que "la cultura y la identidad son inventivas y móviles. No necesitan echar raíces en tramas ancestrales; viven por polinización, por transplante (histórico)”. (Ibidem: 30). Para otros, denota precisamente lo contrario, que cultura e identidad no son lo mismo y que la última se nutre de la primera, pues ella tiene carácter más permanente. Bajo este marco general, la contradicción no parece ser entre esencia y cambio, ni siquiera entre mismidad y alteridad, sino que entre cultura del poder y contra-cultura desde la exclusión. Es la contradicción entre el poder chileno y el contra-poder mapuche, aunque no se reduce ni a una dimensión ni a una conflagración étnica, puesto que el poder es, sobre todo, económico y político y, por cierto, tanto la cultura como la identidad se constituyen desde el poder. Y esto es cabalmente comprendido y nítidamente articulado por el Estado-nación chileno y por los principales actores del modelo eco- 
nómico, y es por ello que se plantea que "bajo ningún motivo, bajo ninguna circunstancia entregaremos la tierra a los mapuche, no tienen la capacidad para cultivarla” o, que "no existe deuda histórica, lo que se perdió, se perdió” (Tricot, 2006). Y lo que se perdió no es poco, no sólo en términos cuantitativos, sino que, por sobre todo, en términos cualitativos, puesto que para los mapuche la tierra y el territorio están profunda e indisolublemente vinculados a su historia, su cultura y, por ende, a su pervivencia como pueblo. Por lo mismo, cuando los mapuche sienten amenazado su territorio, sienten amenazada su mera existencia, entonces se refugian en su etnicidad, en su calidad de pueblo-nación originario y en la comunidad, que se transforma en el espacio ancestral por antonomasia, aunque, en rigor, las actuales comunidades son los remanentes de las antiguas reducciones impuestas por el Estado chileno con posterioridad a la ocupación militar del territorio mapuche. Pero, la comunidad es componente integral del territorio -aunque un porcentaje significativo de los mapuche viva en las zonas urbanasy, acaso, la más importante simbólicamente. Allí se producen y reproducen antiguas prácticas culturales y se hallan los lugares sagrados, como el Rewe y el Nguillatuwe, donde se realizan los principales ritos y rogativas, tales como Nguillatun, Llelipun, Kamarikun y Machitun. Es en la comunidad también -aunque probablemente en un número reducido de ellas-donde se fortalece la identidad y se articula la misma a las demandas del movimiento mapuche mediante la producción y reproducción de múltiples significados. Estas constelaciones de significado -acorde a Mascareño- "son iterables, contingentes e históricamente formadas; las autodescripciones en cambio pueden seguir recurriendo a una idea de inviolabilidad cultural o identitaria si las circunstancias políticas así lo exigen”, (Mascareño Ibid.: 73) pero dicha aseveración pareciera no establecer diferencia alguna entre cultura e identidad. Además, utiliza como objeto de crítica un concepto estático, irrepetible e integrado de cultura, precisamente lo que rechaza, lo cual no necesariamente es lo que acontece con el movimiento mapuche, aunque no pueden obviarse algunas representaciones con rasgos esencialistas que efectivamente se dan. Es más, Mariman (Mariman José, 2003 )califica a algunos dirigentes de esencialismo nostálgico o cósmico por su representación de la cultura e identidad mapuche y, por su parte -en relación a la memoria histórica- Naguill impugna la historia Ercillana "no porque esta pueda narrar hechos poco verídicos o alabe héroes mistificados, sino porque ha servido para idealizarnos y relegarnos a un pasado antiguo, escamoteando nuestro pasado más reciente, aquel en que la libertad mapuche cruzaba la cordillera de los Andes y trazaba rutas en las costas del Pacífico y el Atlántico. Esa parte de la historia que nos permitiría dimensionar mejor lo que nos ha sido arrebatado” (Naguill, 2007). Es decir, se reivindica la memoria y la acción reciente, más que un pasado remoto, pero a partir de un conocimiento y reconocimiento de una matriz cultural que, también, les ha sido arrebatada. Y esa matriz cultural remite al Mundo y País mapuche y a una narrativa identitaria que se construye desde esa base objetiva y no sólo por razones políticas instrumentales. Sustento cultural que no suprime ni omite, ni menos aún ocluye, el cambio y las rupturas, como tampoco hiperboliza las continuidades. Se trata, en suma, de no olvidar que existen o persisten capas subterráneas que conforman el Ser mapuche actual, constituyen un 
elemento común que estructura una continuidad histórica donde se engarzan continuidades y transformaciones, remitiendo siempre a la cultura, entendida en este contexto como "la intersección de experiencias sociales e imaginarios colectivos”( PNUD, 2002: 36). El mapuche vive y revive su cultura, la construye y reconstruye, no sólo a través del movimiento sociopolítico, sino que en su cotidianidad, en la experiencia social que vincula, de alguna manera, a su representación de cultura y a su relato identitario. Para Archer el status de la cultura oscila entre el de una variable absolutamente independiente, el poder de rango superior de la sociedad a una posición de dependencia supina con respecto a otras instituciones sociales. Por lo mismo, no ocupa un lugar claro en el análisis sociológico. Existe una ciénaga conceptual, no obstante, para el mapuche no existe "ciénaga conceptual” en relación a la cultura, simplemente la vive, la siente, la recuerda, la internaliza, la transmite, la reproduce, la cuida, pues es el útero desde donde se alimenta para enfrentar la sempiterna subsistencia en la única marisma que conoce, aquella de la mismidad discriminada y de la alteridad colonizadora. Porque el Estado chileno teme al otro, lo reprime y coloniza en la forma de asimilación forzada. El mapuche, por su parte, responde desde su Mundo y desde su País construido hace milenios y reconstruido a retazos bajo el fuego incesante de modernos arcabuces en Temulemu, LleuLleu, Cuyinco, Collipulli, Lumako, Chol-Chol, sin embargo, tanto el Mundo como el País mapuche insisten en no fenecer, quizás por la persistencia de la propia cultura ancestral, tal vez por la tenacidad de la identidad fraguada desde esa cultura antigua previa al Piam de Xeg-Xeg y Kay-Kay, o quizás por ambas cosas y, además, por la acción colectiva del movimiento mapuche que conjuga los elementos de resistencia y (re)construcción como dos componentes centrales de su estrategia de lucha política.

\section{La (re) construcción del Mundo y País mapuche a pesar de todo}

Sonriéndole al rocío, y derramando sus pájaros ámbar sobre los anhelantes sembradíos, el nuevo sol emerge cada año nuevo mapuche. Al We Xipantu le esperan ansiosos y respetuosos en el cántico de la medianoche, en el danzar alrededor del Rewe, orgullosos y respetuosos ante el inicio de un nuevo ciclo de la naturaleza. Una nueva etapa de las vidas del árbol, del riachuelo, del monte, del anciano y del niño, en la esperanza que todo sea mejor en el sargazo de su existencia. Si, pues el pueblo mapuche subsiste en la certidumbre de su pasado de pueblo originario, pero en la incertidumbre de su futuro en un sistema cultural, económico y político que le han impuesto a la fuerza. Teresa Painequeo, de Reñico Chico, se hizo machi hace más de dos décadas cuando "me mataron un día entero y de ahí me levantaron” (Painequeo, 1999). Del mismo modo, al pueblo mapuche lo han matado siglos enteros, pero se ha levantado una y otra vez. Y tal espíritu soliviantador, es posible argumentar, no puede ser explicado sólo con referencia a una identidad construida con objetivos políticos o a una cultura que construye una imagen unitaria -una ficción lograda-de aquello que 
entienden los une y que les permite afirmar su posición frente a otros que son señalados como ajenos a lo propio, es decir, como otros que se autodescriben por medio de otra cultura. Porque, si así fuese, la voz de la machi sería sólo instrumental y coyuntural y se pronunciaría en un vacuum cultural; sería tan sólo un discurso acerca de la tierra, pero no desde la tierra; acerca del Mundo mapuche; pero no desde el Mundo mapuche; acerca del País mapuche, pero no desde el País mapuche. Sería, en definitiva, semántica cultural y no cultura. Lo anterior no significa que la cultura sea una totalidad impenetrable ni que el movimiento mapuche lo considere así, sino, más bien, que la cultura posee cierta materialidad que trasciende las subjetividades individuales y desde donde se nutren los procesos de (re)construcción identitaria. Por lo demás, tanto en la conceptualización del Mundo mapuche y, especialmente, en la de País mapuche, es posible constatar heterogeneidad en la noción y praxis de las identidades territoriales, aunque como se ha señalado, siempre preservando elementos culturales comunes a todas ellas. En este sentido, la imagen de coherencia e integración cultural no pareciera ser sólo un relato desde el movimiento mapuche a fin de resaltar la unidad y minimizar las diferencias, sino que la naturalización en el discurso político de una realidad externa. Realidad, en cualquier caso, violentada por el conquistador hispano y chileno que, en el caso especifico del Estado nacional, ha transitado por el derrotero de la asimilación forzada, desde la reducción a la criminalización. Y es precisamente esta realidad de dominación y subordinación la que busca transformar el movimiento mapuche constituyéndose como un nuevo sujeto social y político a partir de la elaboración de un repertorio de demandas distinto, donde la territorialización de la demanda indígena es central en la posibilidad de (re) construirse como pueblo-nación. Porque sin territorio no puede haber autonomía y sin autonomía no puede haber territorio y sin ambos no puede haber ni Mundo ni País mapuche.

Es un sueño inconcluso, como su cultura intervenida, como su identidad fragmentada, como su maculada memoria. Y el movimiento mapuche parece haber recurrido a esa memoria para re-escribir la historia a través de la elaboración de marcos cognitivos que proponen una lectura distinta de la realidad, construyen identidad e impulsan la acción colectiva. Tal vez por ello es que las fúlgidas lenguas de fuego crepitan en el abrumador silencio del amanecer. Quizás esperando la antigua historia de los antiguos, tal vez el beso eterno de los amantes o, simplemente, el meloso sueño de las estrellas. Sin embargo, en lontananza irrumpe el wingka armado hasta los dientes y, una vez más, el mapuche se refugia en la comunidad de la sangre y de la tierra, porque en esos momentos de crisis su cultura, sin adjetivos o apelativos, sin fisuras, o acaso con ellas, se le aparece con toda la fuerza de la mujer estrella de tiempos inmemoriales. El tiempo del Mundo mapuche que se transformó en Wallmapu. 


\section{Bibliografía}

Archer M, (1997), Cultura y Teoría Social, Ediciones Nueva Visión, Buenos Aires.

Bello Álvaro (2004), Etnicidad y ciudadanía en América Latina, La acción colectiva de los pueblos indígenas, CEPAL, Santiago.

Benjamín W., Tesis de Filosofía de la Historia, Revolta Global, http:// www.revoltaglobal.net

Chihuailaf E. (2008), “Nuestra lucha es una lucha por ternura”, en Historias y luchas del pueblo mapuche, Editorial Aún creemos en los sueños, Santiago.

Clifford J. (1995), Dilemas de la Cultura, Antropología, literatura y arte en la perspectiva posmoderna, Gedisa, Barcelona.

Hernández I, (2003), Autonomía o Ciudadanía incompleta, el Pueblo Mapuche en Chile y Argentina, Pehuén Editores, Santiago.

Larraín J. (2007), "Sobre sociología de la cultura: la deconstrucción de lo mapuche, de Aldo Mascareño”, Estudios Públicos No 105, Santiago.

Ídem (1996), Modernidad, Razón e Identidad en América Latina, Editorial Andrés Bello, Santiago.

Loveman B y Lira E. (2001), "Políticas de la Verdad en Chile 1891-1991 en, Lira E. et al, Historia, política y ética de la verdad en Chile, 18912001, Reflexiones sobre la paz social y la impunidad, LOM Ediciones, Santiago.

Marileo A (1998), El Mundo Mapuche, un mundo de equilibrio y armonía, Corporación de Desarrollo y Comunicaciones Mapuche Xeg-Xeg, Temuco.

Mariman J. (2003), Identidad Fragmentada, Periódico mapuche Azkintuwe, Temuco.

Mariman P. et al (2006), Escucha Wingka , LOM Ediciones, Santiago.

Ídem. (2003) “Prólogo” en Hernández I, Autonomía o Ciudadanía incompleta, el Pueblo Mapuche en Chile y Argentina, Pehuén Editores, Santiago.

Mascareño A (2007), “Sociología de la cultura; deconstrucción de lo mapuche”, Estudios Públicos $N^{\circ} 105$, Santiago.

Melucci A. (1994), “Asumir un compromiso: identidad y movilización en los movimientos sociales”, Zona Abierta $N^{o}$ 69, Madrid. 
Milos P. (2000), "Memoria colectiva: entre la vivencia histórica y la significación”, en Olguín M. et al, Memoria para un nuevo siglo. Chile, miradas a la segunda mitad del siglo XX, LOM Ediciones, Santiago.

Mouffe Ch. (2003), La paradoja democrática, Gedisa, Madrid.

Naguil V. (2007), La memoria y la libertad, último alzamiento mapuche, Periódico Mapuche Azkintuwe, Temuco.

Pavez J, compilador (2008), Cartas mapuche, Siglo XIX, Colecciones Colibrí/Ocho Libros Editores, Santiago.

Raschke J (1994), “Sobre el concepto de movimiento social”, Zona Abierta $N^{\circ}$ 69; Madrid.

Ricceur P. (2000), La memoria, la historia, el olvido, Fondo de Cultura Económica, Buenos Aires.

Rojo G. (2006), Globalización e identidades nacionales $y$ postnacionales...¿de qué estamos hablando?”, LOM Ediciones, Santiago.

Ídem. (2003), Postcolonialidad y nación, LOM Ediciones, Santiago.

Ruiz C. (2007), “Autonomismo mapuche (1907-1992), Renuevos de un tronco antiguo”, en Revista de Historia Social y de las Mentalidades, Pueblo Mapuche: Derechos Colectivos, Departamento de Historia, Universidad de Santiago de Chile, Año XI, Volumen 1, Santiago.

Saavedra A (2002), Los mapuche en la sociedad chilena actual, LOM Ediciones, Santiago.

Toledo V- (2007), "La memoria de las tierras antiguas tocando a las puertas del derecho. Políticas de la memoria mapuche en la transición chilena”, en Revista de Historia Social y de las Mentalidades, Pueblo Mapuche: Derechos Colectivos, Departamento de Historia, Universidad de Santiago de Chile, Año XI, Volumen 1, Santiago.

Tricot T. (2009), "Lumako: punto de inflexión en el desarrollo del nuevo movimiento mapuche”, Revista de Historia Actual, Número 19, Primavera, 2009.

Ídem. (2008), “Identidad y Política en el nuevo Movimiento Mapuche”, Revista Historia Actual Online, Número 15 (Invierno, 2008).

Ídem. (2006), La Lucha del Pueblo Mapuche, Ediciones Ilwen, Chile, Santiago.

Tricot Tokichen (2007), El movimiento mapuche: una aproximación general a través de los diversos enfoques de la teoría de la acción colectiva, Tesis de Magíster, Universidad de Salamanca, Salamanca. 


\section{Documentos}

Informe sobre el Desarrollo Humano en Chile, Programa de las Naciones Unidas para el Desarrollo Humano, Chile, 2002.

Propuesta de Organizaciones Territoriales Mapuche al Estado de Chile, Wallmapu, Pegun 2006.

Vicuña Mackenna B, La conquista de Arauco, discurso pronunciado en la Cámara de Diputados, 10 de agosto 1868.

\section{Entrevistas}

Millalen J. (2009), historiador mapuche, entrevista personal, Temuco.

Ñanko G. (2009), machi mapuche, entrevista personal, Nueva Imperial.

Painemal W. (2009), sub-director del Periódico Mapuche Azkintuwe, entrevista personal, Temuco.

Painequeo T. (1999), machi mapuche, entrevista personal, Reñico Chico, Lumako.

Quilaqueo G. (2009), presidente partido nacionalista mapuche, Wallmapuwen, Temuco.

Reiman G. (2007), dirigente Identidad territorial nagche, entrevista personal, Santiago.

Ídem (2009), entrevista personal, comunidad we Juan Maika, Traiguen 


\section{Glosario}

Ad Mapu: Sistema de regulación del comportamiento individuad y colectivo Epew: Relato

Gempin: Dueño de la palabra; Guardián de la filosofía mapuche

Gulumapu: Chile

Fütran Newen: Gran energía o espíritu

Itrofillmongen: Todo el sistema de vida

Kamarikun: Rogativa mapuche

Kimche: Sabio mapuche

Kimun: Sabiduría

Küme Felen: Bienestar en armonía

Küme Mongen: Calidad de vida

Küpan: Ascendencia sanguínea

Lafkenche: Mapuche de la costa

Lagmien: Mujer, hermana

Llelipun: Rogativa mapuche

Machitun: Rogativa de sanación realizada por la machi

Mapudungun: Idioma mapuche

Meli Witran Mapu: Los cuatro puntos cardinales

Nagche: Mapuche de las tierras bajas

Nag Mapu: La tierra

Newen: Energía, fuerza, espíritu

Nguillatun: Rogativa mapuche

Nguillatuwe: Lugar sagrado donde se realiza el Nguillatun

Nor Felen: Ley de autorregulación de la naturaleza

Ñuke Mapu: Madre Tierra

Pentukun: Diálogo

Pewenche: Mapuche de la cordillera

Piam: Relato que remite a los orígenes

Puelche: Mapuche del Puelmapu

Puelmapu: Argentina

Ruka: Casa

Rewe: Altar ceremonial

Tüwun: Ascendencia territorial

Wallmapu: País mapuche

Wenteche: Mapuche arribanos

We Tripantu: Año nuevo mapuche

Williche: Mapuche del sur

Wingka: Ladrón, extranjero. Por extensión, chileno 